Enferm Brasi2019;18(1):85-94

http://dx.doi.org/10.33233/eb.v18i1.2504

\title{
ARTIGO ORIGINAL \\ Cuidado centrado na família do recém-nascido: alegações dos profissionais de saúde
}

Patricia Rejane Ribeiro Bispo, M.Sc. ${ }^{*}$, Isabel Lopes Pereira da Silva Amaral ${ }^{* *}$, Maria da Conceição Luna dos Santos, M.Sc.*, Josicleide Montenegro da Silva Guedes Alcoforado, M.Sc. ${ }^{*}$, Maria Gorete Lucena de Vasconcelos, D.Sc. ${ }^{* *}$

*Universidade Federal de Pernambuco, **Pós-Graduada em Saúde Pública com Ênfase em Saúde da Família pela Faculdade de Comunicação e Turismo de Olinda, ${ }^{* * *}$ Pós-Doutora em Enfermagem em Saúde Pública pela Escola de Enfermagem de Ribeirão Preto

Recebido em 5 de setembro de 2018; aceito em 5 de dezembro de 2018.

Endereço de correspondência: Isabel Lopes Pereira da Silva Amaral, 1aㅡ Travessa Santa Catarina, 25, 53620-373 Saramandaia, Igarassu PE, E-mail: isabel20ilps@yahoo.com.br; Patricia Rejane Ribeiro Bispo: patriciarrbispo@hotmail.com; Maria da Conceição Luna dos Santos: cecaluna4@gmail.com; Josicleide Montenegro da Silva Guedes Alcoforado, josialcoforado@hotmail.com; Maria Gorete Lucena de Vasconcelos: mariagoretevasconcelos@gmail.com

Artigo retirado da dissertação intitulada: Cuidado Centrado na família do recém-nascido: alegações de profissionais de saúde de autoria de Patricia Rejane Ribeiro Bispo, sob a orientação de Profạ. Mํa Gorete Lucena de Vasconcelos do Programa de Pós-Graduação em Saúde da Criança e do Adolescente da UFPE

\section{Resumo}

Objetivo: Analisar as alegações dos profissionais de saúde sobre o cuidado centrado na família do recém-nascido. Métodos: O estudo foi do tipo descritivo/exploratório, de natureza qualitativa. Fizeram parte do estudo nove profissionais de saúde da unidade de terapia intensiva neonatal do Hospital das Clínicas da Universidade Federal de Pernambuco (HC/UFPE) no período de abril a maio de 2010 , tendo por base a saturação teórica dos dados. A coleta de dados se deu por meio de entrevista semiestruturada orientada por três questões norteadoras. As entrevistas foram analisadas utilizando-se a análise de conteúdo, modalidade temática proposta por Minayo. Resultados: Foram identificadas 4 categorias: Família: elo para o bem-estar, a saúde e a cidadania do pequeno ser; A família como apoio materno; Inclusão insuficiente da família; Alegações ambivalentes sobre o cuidado centrado na família. Conclusão: Os profissionais demonstraram reconhecer a importância do cuidado centrado na família, mas a prática resumiu-se em orientações e inclusão no cuidado direto. A carência de profissionais no setor foi um ponto desafiador. Os próprios profissionais apresentaram soluções como encontros educativos para melhora nesse cenário.

Palavras-chave: relações profissional-família, recém-nascido, enfermagem neonatal, saúde da família.

\footnotetext{
Abstract

Care centered on the family of the newborn: allegations of health professionals

Objective: To analyze the health professionals' claims about care centered on the family of the newborn. Methods: The study was descriptive / exploratory, qualitative in nature. Nine health professionals from the neonatal intensive care unit of the Hospital das Clínicas of the Federal University of Pernambuco (HC / UFPE) from April to May 2010 were part of the study, based on the theoretical saturation of the data. The data collection took place through a semi-structured interview guided by three guiding questions. The interviews were analyzed using the content analysis, thematic modality proposed by Minayo. Results: We identified four categories: Family: link to the welfare, health and citizenship of the small being; The family as maternal support; Insufficient inclusion of the family; Ambivalent claims about family-centered care. Conclusion: Professionals demonstrated the importance of family-centered care, but the practice was summarized in guidelines and inclusion in direct care. The shortage of professionals in the
} 
industry was a challenging point. The professionals themselves presented solutions as educational meetings to improve this scenario.

Key-words: professional-family relations, infant newborn, neonatal nursing,

\section{Resumen \\ Cuidado centrado en la familia del recién nacido: alegaciones de los profesionales de la salud}

Objetivo: Analizar las alegaciones de los profesionales de la salud sobre el cuidado centrado en la familia del recién nacido. Métodos: El estudio fue del tipo descriptivo / exploratorio, de naturaleza cualitativa. Nueve profesionales de salud de la unidad de terapia intensiva neonatal del Hospital de las Clínicas de la Universidad Federal de Pernambuco (HC/UFPE) participaron del estudio en el período de abril a mayo de 2010, teniendo como base la saturación teórica de los datos. La recolección de datos se dio por medio de una entrevista semiestructurada orientada por tres cuestiones orientadoras. Las entrevistas fueron analizadas utilizando el análisis de contenido, modalidad temática propuesta por Minayo. Resultados: Se identificaron 4 categorías: Familia: vínculo para el bienestar, La salud y la ciudadanía del pequeño ser; La familia como apoyo materno; Inclusión insuficiente de la familia; Alegaciones ambivalentes sobre el cuidado centrado en la familia. Conclusión: Los profesionales demostraron reconocer la importancia del cuidado centrado en la familia, pero la práctica se resumió en orientaciones e inclusión en el cuidado directo. La carencia de profesionales en el sector fue un punto desafiante. Los propios profesionales presentaron soluciones como encuentros educativos para mejorar en ese escenario.

Palabras-clave: relaciones profesional-familia, recién nascido, enfermería neonatal, salud de la familia.

Ao longo da história, a assistência ao recém-nascido $(\mathrm{RN})$ que tinha como foco no passado, apenas, o avanço tecnológico e o controle da doença com o objetivo de maior sobrevida do neonato vem sofrendo transformações neste modelo biotecnológico despertando para uma nova filosofia de cuidado, centrando-o na família, tendo como finalidade ampla à capacitação, o empoderamento e a qualidade de vida da tríade mãe/recém-nascido/família [1].

No ciclo familiar mudanças dramáticas podem ocorrer quando acontece o nascimento inesperado de uma criança doente, pois a necessidade de cuidados especializados com consequente hospitalização prolongada, talvez por meses a fio, revela sempre momentos difíceis para mães e familiares, permeados por sentimentos de ansiedade, tristeza, medo, dúvida ou revolta, frente à experiência de ter um filho em situação de risco. A situação vivida faz com que a família procure apoio formalmente nos profissionais de saúde e informalmente com outros familiares, amigos, vizinhos, inclusive, na religião, para suportar as dificuldades da experiência de ter o filho hospitalizado [2].

Estudo realizado sobre o cuidado centrado na família (CCF) demonstra as repercussões sobre o crescimento e o desenvolvimento de crianças prematuras, reduzindo 0 comportamento de stress, possibilitando rápido retorno ao estado de sono e menor utilização de recursos, quando comparadas com crianças cujas famílias não se constituíram no foco da atenção, no qual os neonatos receberam apenas os cuidados de rotina [3].

Gradativamente, estas transformações na filosofia e nas abordagens do cuidado em saúde estão sendo incorporadas às diretrizes das políticas públicas sociais através do Programa Nacional de Humanização da Assistência Hospitalar (PNHAH). Esse tem o objetivo de melhorar a qualidade e a eficácia dos serviços por meio do aprimoramento das relações entre profissionais de saúde e comunidade assistida, valorizando a dimensão humana e a subjetiva, agregando à eficiência técnica e científica uma ética que considere e respeite a singularidade das necessidades do sujeito no ambiente hospitalar [4].

É necessário informar os pais sobre o plano de tratamento e procedimentos realizados, responder aos seus questionamentos com honestidade, ouvir atentamente seus medos e suas expectativas e assisti-los na compreensão das respostas da criança durante a hospitalização, tendo inclusive, a confirmação da importância do suporte que a enfermagem proporciona no atendimento das necessidades dos pais de crianças prematuras [5].

A concepção de trabalhar com o neonato de risco fundamentado nos princípios do cuidado centrado na família pode restabelecer a competência parental, ajudar a equipe de 
profissionais a respeitar valores e sentimentos dos familiares e contribuir para que os pais e profissionais trabalhem em parceria na unidade neonatal [6].

Mesmo em outros contextos e situações, o que os profissionais de saúde passam através do cuidado com foco na família, talvez esteja além da comunicação verbal, evidenciado pela manifestação de interesse pela pessoa do paciente, a troca de experiência entre os envolvidos no processo, a força de coesão da equipe de profissionais, contendo nesta atividade um potencial regenerador considerável ou terapêutico, quando utilizado de forma adequada e efetiva para melhoria da qualidade da assistência [7].

Contudo, as investigações pouco têm explicado o que os profissionais que estão no cotidiano das Unidades de Terapia Intensiva Neonatal (UTIN) entendem e alegam sobre esse processo de trabalho tão discutido nos últimos anos. Esta lacuna desencadeou os seguintes questionamentos de pesquisa a serem investigados pelo estudo em questão: Qual o conhecimento da equipe de saúde neonatal sobre o cuidado centrado na família? Como a família é incluída nesse cuidado?

Ante o exposto, o presente estudo teve como objetivo analisar as alegações dos profissionais de saúde sobre o cuidado centrado na família do recém-nascido.

Material e métodos

Para contemplar o objetivo do estudo, optou-se pelo estudo do tipo descritivo e exploratório de natureza qualitativa. A metodologia foi escolhida por ter como finalidade proporcionar maiores informações sobre o assunto investigado, descrevendo as alegações dos profissionais envolvidos no cuidado ao recém-nascido hospitalizado com a família deste [8].

Esta pesquisa faz parte de um projeto de âmbito maior que tem como título "Estudo Epidemiológico e Avaliação Qualitativa com a família do recém-nascido prematuro em Recife".

A investigação ocorreu na UTIN do Hospital das Clínicas da Universidade Federal de Pernambuco (HC/UFPE), localizado no município de Recife e tem como função básica apoiar o ensino de graduação e pós-graduação do Centro de Ciências da Saúde da UFPE. O HC atua como hospital escola e centro de pesquisa científica; integra o SUS, com prestação de serviços médico-hospitalares e atendimento ambulatorial à população do estado e da região Nordeste. É considerado referência para o atendimento da gravidez e do recém-nascido de alto risco.

Em 2000, o hospital recebeu o título de Hospital Amigo da Criança, iniciativa da Organização Mundial de Saúde (OMS) e do Fundo das Nações Unidas para a Infância (UNICEF), e em 2003 foi instituído um Grupo de Apoio a Mãe Acompanhante (GAMA), dentro dos princípios do cuidado centrado na família, que desenvolve atividades de escuta e de lazer, ajudando a manter o vínculo afetivo da tríade mãe/recém-nascido/família, se consolidando como um espaço inovador de pesquisa.

Os sujeitos do estudo foram nove profissionais da UTIN que atenderam os critérios de inclusão adotados no estudo: trabalhar diretamente com o recém-nascido de risco na instituição e ter vínculo efetivo. Foram excluídos residentes, alunos de graduação ou voluntários. Definiu-se, ainda, como critério de exclusão os profissionais que estavam afastados do serviço, por licença formal ou por férias.

O período da coleta dos dados deu-se nos meses de abril e maio de 2010.

O instrumento utilizado para a coleta de dados foi uma entrevista elaborada pelas próprias autoras, contendo 16 questões, sendo 13 questões referentes à identificação e caracterização dos participantes e as demais relacionadas à exploração do significado para o profissional acerca do processo de trabalho centrado na família, dando margem também para colocações que os sujeitos achassem pertinentes.

As entrevistas foram individuais, mediante autorização prévia dos participantes, realizadas em seu ambiente de trabalho, em local reservado, conforme disponibilidade do entrevistado, quanto à data e horário, gravadas em aparelho MP4 com duração média de 15 minutos e transcritas logo após a sua realização. Foi salientado que a participação de cada um em nada influenciaria no seu vínculo e ambiente de trabalho. Ao término da entrevista a mesma foi exibida ao entrevistado com o objetivo da validação inicial do estudo junto ao profissional.

As entrevistas foram submetidas à análise de conteúdo, na modalidade de análise temática, que revela como conceito central o tema, e este pode ser representado por uma palavra, uma frase ou um resumo. Foi seguida a trajetória de análise de conteúdo temático proposta por Minayo, com o cumprimento das etapas: Primeira etapa - leitura exaustiva das 
entrevistas na íntegra; Segunda etapa - exploração do material; Terceira etapa - síntese interpretativa de toda a análise realizada [9].

Atendendo a Resolução 196/96 do Conselho Nacional de Saúde/Ministério da Saúde (CNS/MS), o projeto foi apreciado pelo Comitê de Ética em Pesquisa do Centro de Ciências da Saúde da Universidade Federal de Pernambuco (CEP/CCSUFPE), obtendo parecer favorável em 07/05/2009, com número do Certificado de Apresentação para Apreciação Ética - CAAE 0056.0.172.000-9.

\section{Resultados e discussão}

Os sujeitos eram do sexo feminino, com idade variando entre 31 e 51 anos e tempo de serviço na instituição entre 02 e 17 anos. Das nove entrevistadas, duas não tinham filhos, mas pretendiam ter e as demais tinham de um a dois filhos, com nenhum nascimento de risco. Quanto ao estado civil, duas eram solteiras, seis casadas, uma divorciada e uma com união estável. Com relação à escolaridade, três possuíam curso superior e as demais, curso técnico.

\section{Família: elo para o bem-estar, saúde e a cidadania do pequeno ser}

Essa temática resultou do questionamento aos profissionais de como eles enxergavam o papel dos familiares na internação do seu recém-nascido de risco. Os entrevistados reconheceram que a presença da família na rotina da UTIN, conversando, apoiando e tocando a criança é uma forma de humanizar a assistência estimulando essa interação:

\footnotetext{
A família é importante pela humanização em si, do apoio, da conversa, do toque do bebê, entendeu? Eu acho que a família estando presente isso aí é estimulado. (E-1)

É importante essa interação. Eu vejo o lado, assim, humano, da formação da criança, desde que ela é gerada, é importante ela ter aquele contato com o pai, que tinha na barriguinha, ouvindo a voz, o toque da mãe, do pai na barriga $[$ E isso tem que continuar, não pode parar! ... Ela precisa receber carinho, atenção. (E-2)
}

De acordo com estes recortes de falas, pode-se concluir que o convívio foi mencionado como importante fator para que a relação criança/família fosse promovida, em especial com a mãe, configurando assim, a importância da manutenção do vínculo da criança com os pais mesmo na situação da UTIN, onde o filho se encontra enfermo.

[...] É importante pelo vínculo. Tudo que passa para o bebê. Mesmo ele não tendo todo entendimento, raciocínio, ele sente o toque da mãe, ele escuta a voz da mãe, que ele escutava quando estava dentro da barriga. (E-3)

No meu ponto de vista, acho que tem que haver essa interação, deve haver, de pais com o seu filho, principalmente o prematuro $[$ ] faz bem para eles. (E-2)

Este contato pode ser constituído como a origem principal do bem-estar, da segurança e da afetividade, dando ao $\mathrm{RN}$ a capacidade de procurar novas vivências, influenciando, basicamente, todos os demais relacionamentos. Esse vínculo fundamenta a capacidade para formar toda ligação profunda e intensa com uma pessoa [10].

Os entrevistados compreenderam que o vínculo afetivo entre a família e o RN é uma estratégia que reduz o estresse emocional tanto da criança como da família. Wright \& Leahey confirmam esse raciocínio e são enfáticas ao dizerem que os profissionais tanto podem diminuir o processo de cura como podem aumentar a promoção da mesma. Para isso basta eles elegerem qual será o tipo de assistência prestada ao seu paciente, com ou sem a interação da família [11]. Os profissionais entrevistados repassaram ter esse conhecimento através dos seguintes depoimentos:

[...] eu acho que é importante os familiares virem dar o apoio, pra recuperação da criança. Porque a família estando presente, é mais fácil. (E-1)

A família com certeza é fundamental... É importante pra saúde física. Acho que é fundamental do ponto de vista emotivo e consequentemente do ponto de vista físico mesmo, porque eu acho que a criança com o apoio, qualquer pessoa com apoio, vai se recuperar melhor. (E-5) 
Por estes relatos, os profissionais demonstraram avaliar a influência da interação familiar sobre a causa, a evolução e a cura da doença, como evidenciado também nos depoimentos abaixo:

A gente vê quando existe essa interação, as crianças reagem muito bem e saem daqui mais rápido (do hospital)! (E-2)

Quanto maior for o vínculo entre a mãe, o pai e o bebê, melhor para a recuperação da criança... E o vínculo entre pais e filho, no geral é muito bom e a recuperação do bebê é muito grande. $(\mathrm{E}-6)$

A ligação efetiva entre a criança e seus familiares foi avaliada também como estratégia notável para proporcionar segurança emocional tanto para a família como para o recémnascido. Laços afetivos garantem que as bases psicológicas do futuro adulto sejam mantidas intactas [12] e este benefício foi observado pela maioria dos profissionais em estudo através dos discursos:

[...] Quanto mais a família ficar perto do RN melhor para ele. Porque a meu ver traz mais segurança tanto para ele quanto para a família, porque está sempre ali presente. (E-6)

A família presente é fundamental com certeza, tanto pelo apoio emocional como para a família também. Emocional da mãe, família e do bebê. Questão de estar junto, de estar presente na UTI. Que todo bebê gosta... gosta de se sentir seguro. (E-5)

A importância da família para mim é essa, é fazer com que os pais, os avós, ou quem for, até o bebê, sinta-se seguro e adaptado na nova realidade. (E-4)

As falas dos profissionais, embora por conhecimento do senso comum, evidenciaram o retrato acima descrito em conjunto com o reconhecimento da criança como ser humano, pertencente a uma família e a uma sociedade, revelando preocupação com o seu desenvolvimento.

Eu acho que seria mais a criança como ser humano, de que ela faz parte de uma família, que
as pessoas estão preocupadas com ela. Que aquele indivíduo tem uma importância na família dele, na comunidade sim. (E-7)

Esse ser vai pro seio da família, então se a gente não trabalhar com a família, tudo que a gente tentou construir para entregar o bebê a ela, a sociedade, pra ele se desenvolver, tudo aquilo que se é esperado, não vamos conseguir! (E-8)

Até pra criança ser um cidadão de bem, tranquilo, ele tem que aprender a conviver na sociedade, então tem que haver esse contato (família e RN). Tem que haver essa continuidade! $(\mathrm{E}-2)$

Pelos relatos, percebeu-se uma sintonia de ideias entre as categorias profissionais participantes do estudo quanto à relevância da família presente na hospitalização do RN na UTIN para a saúde física e a formação da criança e bem-estar para o binômio criança/família.

\section{A família como apoio materno}

$\mathrm{Na}$ concepção da maioria dos entrevistados, a presença da família na UTIN é importante não só para o $\mathrm{RN}$, mas também para apoiar a genitora recém-parida que ali se encontra frente aos cuidados possíveis ao filho.

[...] A família estando presente, a mãe vai se sentir mais segura, apoiada na família e posteriormente ela vai sentir mais segurança em tá perto do filho dela, em trazer o leite [ ] aquelas coisas que a gente sabe aqui na UTI. (E-1)

Vivenciar o nascimento de uma criança enferma afeta toda a família e as mães se sentem tensas quando não podem estar com seus parentes, e mais confiantes e aliviadas quando do contrário [13].

[...] Ela (a mãe) tem mais ânimo porque sabe que a família tá perto, pode contar com a família ali.(E-1) 
A mãe fica mais segura e animada com a família por perto para apoiá-la. (E-4)

[...] É extremamente necessário que eles estejam juntos (familiares e mãe) no dia a dia, dando segurança e conforto para a mãe. A mãe fica muito fragilizada aqui (UTIN) né? Tudo é diferente aqui, toda essa estrutura, porque não é a casa delas, desde a alimentação, a cama [ ] tudo é diferente! As pessoas são diferentes. Então a família que vem dar esse apoio a essa mãe, é tudo. A mãe fica mais confiante, mais tranquila, apesar de tá tristinha porque o filhinho tá aqui passando por todo aquele processo. (E-9)

E-8 enfatizou que as mães também carecem desse apoio por permanecerem durante 0 dia inteiro dentro do hospital:

[...] A família tem um papel muito importante. Porque essa mãe é que tá ali $24 \mathrm{~h}$, praticamente morando no hospital, ela precisa de apoio da família. Então não é só a mãe, não adianta. (E-8)

O apoio às mães por parte da família e da equipe de saúde é essencial, mas também é fundamental o fornecimento de informações que facilitem e criem condições necessárias para que elas saibam lidar com seu filho enfermo, percebendo-se, assim, seguras [13]. Os recortes das falas reconheceram essa parceria equipe/mãe como importante e evidenciaram que a consequência desta é uma mãe motivada e que se sente mais útil.

Faço algumas orientações... a gente termina envolvendo ela no dia a dia da criança, nos cuidados. Então elas se sentem motivadas e felizes e começam a contribuir. (E-2)

A gente vai incluindo ela, ela vai se sentindo útil, vendo que ela é importante, vai se preparando, perdendo todo o medo, o temor. (E-3)

Para promover resultados ideais tanto para o $\mathrm{RN}$ como para a mãe, a equipe além de promover cuidados voltados para o desenvolvimento da criança, também deve ajudar a mãe a passar de um sentimento de maternidade incerta para o sentimento de "mãe real" do seu filho.

O acolhimento dos pais possui importância significativa para que as experiências que venham ocorrer durante esse período sejam bem aceitas e o sofrimento, minimizado [14].

\section{Inclusão insuficiente da família}

A internação em UTIN é uma experiência dolorosa para a criança e para os pais, diante disso, a comunicação franca entre profissional e pais alivia o sofrimento do bebê pela assistência conjunta desenvolvida. Nessa perspectiva, as entrevistas evidenciaram a conversa como forma de cuidado ao binômio família/RN, informando e orientando os familiares envolvidos nessa assistência:

Eu procuro sempre conversar com a família, dizer o que tá acontecendo. (E-7)

Aqui a gente já estendeu a visita, então deixar essa família participar do processo, além da mãe, de uma maneira organizada... na medida do possível se consegue dar orientação a essa avó, a esse pai, nesse momento. (E-8)

A comunicação está presente em todas as ações realizadas com o paciente, seja para orientar, informar, apoiar, confortar ou atender suas necessidades básicas. Essa visão fica bem patente na fala de E-5:

A gente pode inserir ela (a família) em muitos aspectos para acompanhar o bebê. Desde chegar, acompanhar o caso clínico dele, saber o que tá acontecendo, como é que vai a evolução, como é que vão os exames, se o bebê tá se recuperando, se o bebê não está se recuperando [ ] assim, tudo! (E-5)

Porém, foi notado que em todas as falas essa comunicação só era estabelecida de forma unidirecional, indo contra um pressuposto do CCF que fala que a informação compartilhada pelos profissionais de saúde deve ter um caráter não apenas de comunicar ao outro, mas sim de dividir as informações imparcialmente para que possam ser tomadas decisões conjuntas (família/paciente e equipe) quando oportuno [3]. 
A comunicação não verbal foi incentivada entre pais e filhos, isso ficou claro nas falas quando eles expressaram estímulo ao toque e ao contato entre o binômio:

[...] (A gente) incentiva o pai a tocar, a mãe também. Quando ele (o RN) não está na oxigenioterapia, a gente procura botar esse bebê pra ele sentir o pai, a mãe junto, os avós [...] Eu acho que é basicamente isso. É esse apoio aí. (E-1)

Fazemos com que o pai tenha contato com o filho [ ] levando o pai junto ao bebê. Pegando o bebê e levando junto da mãe, levando ao lado dela, caso possa ir ao peito, colocamos junto. $(\mathrm{E}-6)$

Geralmente a gente tenta viabilizar essa interação deles, colocar no colinho quando possível, dizer à mãe que é importante o toque dela, para ele se sentir acolhido [...] (E-2)

A comunicação não verbal pode ser definida como toda informação obtida por meio de gestos, posturas, expressões faciais, toque, orientações do corpo e até pela distância do corpo entre os indivíduos [15].

[...] Como hoje mesmo foi o caso, eu quando fiz o banho no leito... Eu fiz questão que a mãe segurasse o bebê, mesmo o menino entubado. Ela estava junto e segurou ali, ficou bem juntinha, quietinha, enquanto eu arrumava a incubadora pra ela. Ela ficou felicíssima [...] (E-9)

As falas dos entrevistados também demonstraram incluir os familiares em sua assistência, integrando-os nos cuidados básicos diretos a criança enferma, como o oferecimento da dieta, a troca da fralda, a realização do banho, envolvendo eles nos cuidados de rotina como forma de prepará-los para a alta:

[...] Tem o momento, no caso, da dieta, a gente ensina, incentiva o pai a segurar a sonda, a seringuinha. $(\mathrm{E}-1)$

E aí a gente diz: vamos lá! A gente já vai treinando para quando você (o familiar) chegar em casa. (E-3)

\section{Alegações ambivalentes sobre o cuidado centrado na família}

O conhecimento e a consciência do processo de cuidado centrado na família receberam grande espaço nas respostas dos entrevistados, mas na prática os resultados foram contraditórios a tal aspecto. Os profissionais relataram não ter o tempo devido para oferecer uma assistência voltada também para a família, por causa do quantitativo escasso de pessoal, resultando numa sobrecarga de trabalho:

Embora se queira, a disponibilidade de colocar isso (o CCF) em prática... a situação não permite. Se não tiver muitos profissionais, isso impossibilita a interação. É um processo que leva tempo, de parar para ouvir e explicar. (E-2)

Eu acho que todos têm essa visão, mas não colocam em prática. Eu acho que é diferente, até porque todo o sistema da gente tem barreira [...] Todo o trabalho de sobrecarga da gente, tudo isso interfere nessa assistência humanizada. (E-3)

Apesar de existir no hospital um Grupo de Apoio as Mães Acompanhantes (GAMA), desde 2003, com o intuito de realizar ações que congregam atividades de escuta e de lazer, ajudando a manter o vínculo afetivo da tríade mãe/recém-nascido/família, se consolidando como um espaço inovador de pesquisa, o envolvimento dos profissionais não é concretizado com a justificativa da falta de pessoal, como descrito na fala abaixo:

Olha, eu acho que falta funcionários aqui na neo... Acho que se existisse um quadro completo de funcionários, esse grupo (GAMA) funcionaria. Porque hoje realmente eu não vejo como tirar uma médica e uma enfermeira daqui de dentro pra fazer esse grupo, na situação que a gente vive entendeu? A sensação é que hoje já existe uma dificuldade do pessoal que tá na chefia de conseguir manter a chefia e a assistência. (E-7)

Para aqueles que conhecem o grupo, fica claro esta falta de envolvimento: 
Aqui tem o GAMA, Grupo de Apoio as Mães Acompanhantes, mas ele não funciona como deveria. Porque falta muito envolvimento dos profissionais. A gente trabalha com déficit de pessoal. Eu gostaria sempre de ir. Quando eu não posso ir, fico preocupada. Às vezes o médico não pode. (E-8)

Eu acredito que esse grupo funciona, apesar de ser um pouco desligada, porque como a gente aqui tem uma rotina muito ativa, a gente não participa muito. Até porque a gente não tem tempo mesmo, condições de tá participando. (E-5)

A falta de interação com o GAMA, apontada pelos profissionais, fica clara nas falas de alguns entrevistados que não sabiam o que realmente o grupo representava ou como funcionava. Mesmo com sete anos de existência, os participantes não demonstraram conhecimento profundo do grupo do qual deveriam fazer parte:

Aqui tem a psicóloga que conversa muito com as mães. Grupinhos onde se escutam elas, as dificuldades delas. Não sei te dizer se é só psicóloga, assistente social... Sei que tem esse papel importante de abordar, ver as dificuldades delas. (E-2)

Tinha um grupo aqui e deixou de ter, acho muito importante essa questão de ter um grupo, de discutir. (E-7)

Aqui, que eu saiba, tem um grupo de apoio as mães que ficam aí acompanhando os filhos. Sai até em jornal [ ] Passeiam [ ] Só para a mãe [ ] E quem participa é a assistente social. (E-3)

Em consequência da presença de poucos funcionários e muitos pacientes, a atenção demandada por familiares que acompanham a internação do RN fica prejudicada em função do pouco tempo disponível dos profissionais. A instituição hospitalar está impregnada ainda do modelo biomédico curativo o que reduz o humano ao biológico, deixando de lado a visão humanística e holística dos cuidados [16].

Assistir a um paciente com a visão do CCF também foi analisada como consciência de cada um, valor atribuido pela natureza de cada ser:

A questão é mais pessoal, natureza do ser humano... Se tenta de toda forma trazer essa pessoa pra essa visão pro nosso dia a dia. Mas é difícil trabalhar o ser humano, porque aí é psicológico de cada um. (E-2)

Os profissionais têm a visão (do CCF), sabem o que é, mas não põem em prática! (E-9) [...] Eu acho que tem alguns profissionais que precisam se trabalhar sim. Principalmente 0 pessoal de nível superior, por incrível que pareça! (E-7)

Eu acho que vai de cada um, ser tocado [ $]$ De querer botar no colo não é? (E-1)

A filosofia do CCF reconhece os profissionais e o serviço de saúde como temporários e flutuantes e a família como uma constante na vida da criança. Consequentemente, duas ações são essenciais segundo essa concepção: a parceria e a negociação com a família [17]. Sobre essa parceria, os entrevistados manifestaram não reconhecê-la na rotina de trabalho de seus colegas da UTIN, descrevendo que os profissionais não gostam nem de repassar as informações sobre a saúde da criança, chegando a apresentarem dificuldade na comunicação:

Acho que alguns (profissionais) deveriam melhorar no contato assim que o bebê chega, pois às vezes as pessoas (profissionais) são muito agressivas com a família... Porque assim que 0 bebê chega, a família fica ansiosa e quer saber como é que tá tudo e as pessoas são muito ríspidas. Eles não dão essas informações. Pessoas até por parte de auxiliar, da enfermeira e do médico. (E-6)

A equipe não tem essa visão (do CCF). Eu vou ser bem sincera com você. Enfermagem tem muita formação desse tipo e mesmo tendo, ainda tem pessoas que têm dificuldade de entrar nesse processo. Mas eu acho que o médico tem mais dificuldade pela própria formação. (E-8)

Em relação a esse ponto, os sujeitos da pesquisa sugerem que sejam implantadas no serviço ações que busquem a sensibilização dos mesmos sobre a ótica do CCF. 
No caso de melhorar, deveriam existir muitas palestras, reuniões onde são abordadas soluções [ $]$ Se tentar de toda forma trazer essa pessoa com essa visão (do CCF) pro nosso dia a dia. $(\mathrm{E}-2)$

Acho que um curso de reciclagem, [] de humanização. Para que seja geral, todo mundo tenha a mesma postura profissional, de quando a família chegar, incentivar. (E-1)

Deve-se fazer trabalho de conscientização dos profissionais [...] Ter mais trabalho de treinamento, como a gente deve se portar. (E-3)

Sobre essa concepção, um estudo aponta que desenvolver pessoas e melhorar a qualidade da assistência à saúde beneficia tanto os trabalhadores como os pacientes, considerando seus direitos como cidadãos contribuindo para melhorar a qualidade de vida de ambos os envolvidos no processo [18].

Transformar a forma de assistir por meio de ações que valorizem a família como parceira no cuidado ao $\mathrm{RN}$ pode ser uma boa maneira de humanizar a saúde.

\section{Conclusão}

Os profissionais de saúde demonstraram reconhecer a família como ponto importante na recuperação e desenvolvimento do $\mathrm{RN}$ a curto e longo prazo. Entretanto, a inserção da mesma limitou-se na informação quando oportuna e no encorajamento a participar do cuidado à criança, apoiando-a.

Ressalta-se que, embora o processo de trabalho da UTI neonatal não facilite a oferta da assistência humanizada, é percebido que alguns trabalhadores desenvolvem ações que facultam essa prática. A ausência de algo concreto que fixe um elo entre os profissionais e a família foi evidenciada quando estes demonstraram desconhecer total ou parcial a existência do grupo de apoio às mães já implantado na instituição campo da pesquisa há alguns anos.

Para todos os problemas apontados como empecilhos para a prática assistencial centrada na família, foi apresentada como solução pelos próprios profissionais a necessidade de se realizar oficinas, cursos de reciclagem, treinamento em serviço. Enfim, encontros educativos pré-agendados que resgatassem ou despertassem a sensibilidade do ser humano em relação às necessidades do outro e a vinculação disso com a saúde da criança.

\section{Referências}

1. Costa R, Padilha MI. Saberes e práticas no cuidado ao recém-nascido em terapia intensiva em Florianópolis (década de 1980). Esc Anna Nery 2012;16(2):247-54. https://doi.org/10.1590/S1414-81452012000200006

2. Carvalho LS, Pereira CMC. As reações psicológicas dos pais frente à hospitalização do bebê prematuro na UTI neonatal. Rev SBPH 2017;20(2):101-22.

3. Corrêa AR, Andrade AC, Manzo BF, Couto DL, Duarte ED. As práticas do cuidado centrado na família na perspectiva do enfermeiro da unidade neonatal. Esc Anna Nery 2015;19(4):629-34. https://doi.org/10.5935/1414-8145.20150084

4. Brasil. Ministério da Saúde. Programa nacional de humanização da assistência hospitalar. Brasília: Ministério da Saúde; 2001.

5. Albert J, Osaku E, Costa CM, Costa JB, Jorge MCTC. Percepção dos pais frente à assistência dos profissionais da saúde na UTI neonatal do hospital universitário do oeste do Paraná. Fiep Bulletin 2014;84(2):1-6.

6. Soares RLSF, Christoffel MM, Rodrigues EC, Machado MED, Cunha AL. Ser pai de recém-nascido prematuro na unidade de terapia intensiva neonatal: da parentalidade a paternidade. Esc Anna Nery 2015;19(3):409-16. https://doi.org/10.5935/14148145.20150054

7. Nascimento CAD, Cartaxo CMB, Monteiro EMLM, Silva LMP, Souto CC, Leão ENC. Percepção de enfermeiros sobre os pais de prematuros em unidade de terapia intensiva neonatal. Rev Rene 2013;14(4):811-20.

8. Kerr LRFS, Kendall C. A pesquisa qualitativa em saúde. Rev Rene 2013;14(6):1061-3.

9. Minayo MCS. Pesquisa social. Teoria. Método e criatividade. 28 ed. Petrópolis: Vozes; 2009. 
10. Brassolatti MM, Veríssimo MLR. A presença dos pais e a promoção do desenvolvimento da criança hospitalizada: análise da literatura. Rev Soc Bras Enferm Ped 2013;13(1):37-45.

11. Wright LM, Leahey M. Enfermeiras e famílias. 5 ed. São Paulo: Roca; 2011.

12. Araújo BBM, Rodrigues BMRD, Pacheco STA. A promoção do cuidado materno ao neonato prematuro: a perspectiva da educação problematizadora em saúde. Rev Enferm UERJ 2015;23(1):128-31. https://doi.org/10.12957/reueri.2015.14779

13. Sampaio PSS, Angelo M. Cuidado da família em pediatria: vivência de enfermeiros em um hospital universitário. Rev Soc Bras Enferm 2015;15(2):85-92.

14. Ramos DZ, Lima CA, Leal ALR, Oliveira VV, Prado PF, Souza AAM et al. A participação da família no cuidado às Crianças internadas em unidade de terapia Intensiva. Rev Bras Promoç Saúde 2016;29(2):189-196. https://doi.org/10.5020/18061230.2016.p189

15. Campos CAC, Silva LB, Bernardes JS, Soares ALC, Ferreira SMS. Desafios da comunicação em Unidade de Terapia Intensiva Neonatal para profissionais e usuários. Saúde Debate 2017;(N. especial):165-74. https://doi.org/10.1590/0103-11042017s214

16. Silva TRG, Manzo BF, Fieroti FCCF, Silva PM. Cuidado centrado na família na perspectiva de enfermeiras da Unidade de Terapia Intensiva Neonatal. Rev Rene 2016;17(5):643-50. https://doi.org/10.15253/2175-6783.2016000500009

17. Balbino FS, Meschini GFG, Balieiro MMFG, Mandetta MA. Percepção do cuidado centrado na família em unidade neonatal. Rev Enferm FSM. 2016;6(1):84-92. https://doi.org/10.5902/2179769216340

18. Barreto MS, Arruda GO, Vivar CG, Marcon SS. Cuidado centrado na família em unidade emergências: percepção de enfermeiros e médicos brasileiros. Esc Anna Nery 2017;21(2):1-7. https://doi.org/10.5935/1414-8145.20170042 